Supporting Information

\title{
Identification of Anomericity and Linkage of Arabinose and Ribose Through Collision Induced Dissociation
}

Shang-Ting Tsai ${ }^{1,2}$, Hock-Seng Nguan ${ }^{1,2}$, and Chi-Kung Ni*1,3

\footnotetext{
${ }^{1}$ Institute of Atomic and Molecular Sciences, Academia Sinica, P. O. Box 23-166, Taipei 10617, Taiwan

${ }^{2}$ Equal contribution to this work

${ }^{3}$ Department of Chemistry, National Tsing Hua University, Hsinchu 30013, Taiwan.

*Email address: ckni@po.iams.sinica.edu.tw
} 


\section{The procedure generating sodiated arabinose and ribose conformers:}

Using the collection of arabinose and ribose conformers, each with different ring puckering index that generated by our in-house program, several sodiated saccharide conformers were created by inserting a sodium ion to a number of possible sodium binding sites, i.e. the locations near lone electron pairs of $\mathrm{O}$-atom on the saccharide. Assuming the tetrahedral geometry of $\mathrm{sp} 3$ orbitals for the $\mathrm{O}$-atom, the direction of their electron lone pairs around the atom were identified. For each O-atom, three positions were considered for sodium ion insertion: two at the two lone pairs and one at the direction that bisecting the angle between the two lone pairs, where the distance between the O-Na+ was set to be $2.5 \AA$. For each hydroxyl O-atom, four different $\mathrm{OH}$ orientations that made up by three $90^{\circ}$ rotation around its $\mathrm{C}-\mathrm{O}$ axis were considered, where the initial $\mathrm{OH}$ orientation is arbitrary. Accordingly, for an initial arabinose or ribose conformer which contains four hydroxyl group and one ether group, there are 51 sodiated saccharide conformer of different ion location were generated. The total numbers of sodiated saccharide conformer generated for each type of saccharide are 1020 and 1938 for its furanose and pyranose ring form, respectively.

\section{The steps of generating the TSs guessed structures:}

There are two steps of generating the TSs guessed structures: 1. H-atom of the donor hydroxyl group $\mathrm{O}_{\mathrm{D}} \mathrm{H}$ was brought near to an acceptor $\mathrm{O}$-atom $\mathrm{O}_{\mathrm{A}}$. 2. Elongating the particular $\mathrm{O}_{\mathrm{A}}-\mathrm{C}$ bond that mimics the dehydration or the ring-opening reaction. From each TS candidate, we generated the corresponding TS guessed structures by three different combinations of the aforementioned two steps. The first combination starts by changing the position of the $\mathrm{H}$-atom of the $\mathrm{O}_{\mathrm{D}} \mathrm{H}$ to position where $\mathrm{H} . . \mathrm{O}_{\mathrm{A}}$ distance become $1.2 \AA$. For the case of dehydration reaction, the $\mathrm{H} . . . \mathrm{O}_{\mathrm{A}}-\mathrm{C}$ angle was designated to be 109 degrees; while for ring-opening reaction the $\mathrm{H} . . . \mathrm{O}_{\mathrm{A}}-\mathrm{C}_{1}$ angle was designated to be 90 degrees. The second step involves elongating $\mathrm{O}-\mathrm{C}$ bond to $1.8 \AA$ by moving three atoms $\left(\mathrm{H} \ldots \mathrm{O}_{\mathrm{A}}-\mathrm{H}\right)$ together in the direction of $\mathrm{O}_{\mathrm{A}}-\mathrm{C}$ bond for case of dehydration, or by moving two atoms $\left(\mathrm{H} \ldots \mathrm{O}_{\mathrm{A}}\right)$ together in the direction of $\mathrm{O}_{\mathrm{A}}-\mathrm{C}_{1}$ bond for the case of ring-opening. For the second combination, the $\mathrm{O}_{\mathrm{A}}-\mathrm{C}$ bond was elongated first to $1.8 \AA$ by moving $\mathrm{O}_{\mathrm{A}}-\mathrm{H}$ in the direction of $\mathrm{O}_{\mathrm{A}}-\mathrm{C}$ for case of dehydration, or simply $\mathrm{O}_{\mathrm{A}}$ in the direction of $\mathrm{O}_{\mathrm{A}}-\mathrm{C}_{1}$ bond for the case of ring-opening. Then, the position of the H-atom from $\mathrm{O}_{\mathrm{D}} \mathrm{H}$ was relocated to be $1.2 \AA$ away from the $\mathrm{O}_{\mathrm{A}}$, where the new location is on the straight line that connects between $\mathrm{O}_{\mathrm{D}}$ and $\mathrm{O}_{\mathrm{A}}$. The third combination is similar to that of the second, except the $\mathrm{O}_{\mathrm{A}}-\mathrm{C}$ bond is elongated to $2.0 \AA$. For some cases where the IRC of the TS did not 
provide the clear link between expected reactants and products, more TS guesses were generated by varying the $\mathrm{O}_{\mathrm{A}}-\mathrm{C}$ elongation from 1.65 to $1.8 \AA$ and optimized again using the DFT/B3LYP method.

\section{Reaction rate constant calculation:}

In CID, there are several distinct conformers of the sodiated saccharides that could contribute to the reaction rates of the two reactions of dehydration and ring-opening, hence their respective mass spectra. Considering these contributions of different conformer, the reaction rate for a particular reaction can be written as

$$
\begin{aligned}
-\frac{d[A]}{d t} & =\sum_{i=1}^{M} k_{i}(T)\left[A_{i}\right] \\
& =[A] \sum_{i=1}^{M} k_{i}(T) P_{i}
\end{aligned}
$$

where $[A]$ denotes the total concentration sodiated saccharide, $\left[A_{i}\right]$ denotes the concentration of conformer with structure $i, M$ denotes the total number of distinct conformers, $P_{i}$ denotes the population probability of conformer $i$, and $k_{i}(T)$ is the temperature dependent reaction rate constant of conformer $i$. At thermal equilibrium, $P_{i}$ is proportional to Boltzmann factor of $e^{-\left(E_{i}-E_{\min }\right) / k_{B} T}$, such that $E_{i}$ and $E_{\min }$ are the energy of the conformer $i$ and the most stable sodiated saccharide of each anomer and ring form, respectively, and $k_{B}$ is the Boltzmann constant. Therefore, the rate constant for each reaction that contributed by various conformers was calculated as $\sum_{i=1}^{M} k_{i}(T) P_{i}$, where the $k_{i}(T)$ is rate constant contributed by $i$-th conformer, which can be calculated using standard transition state theory. 

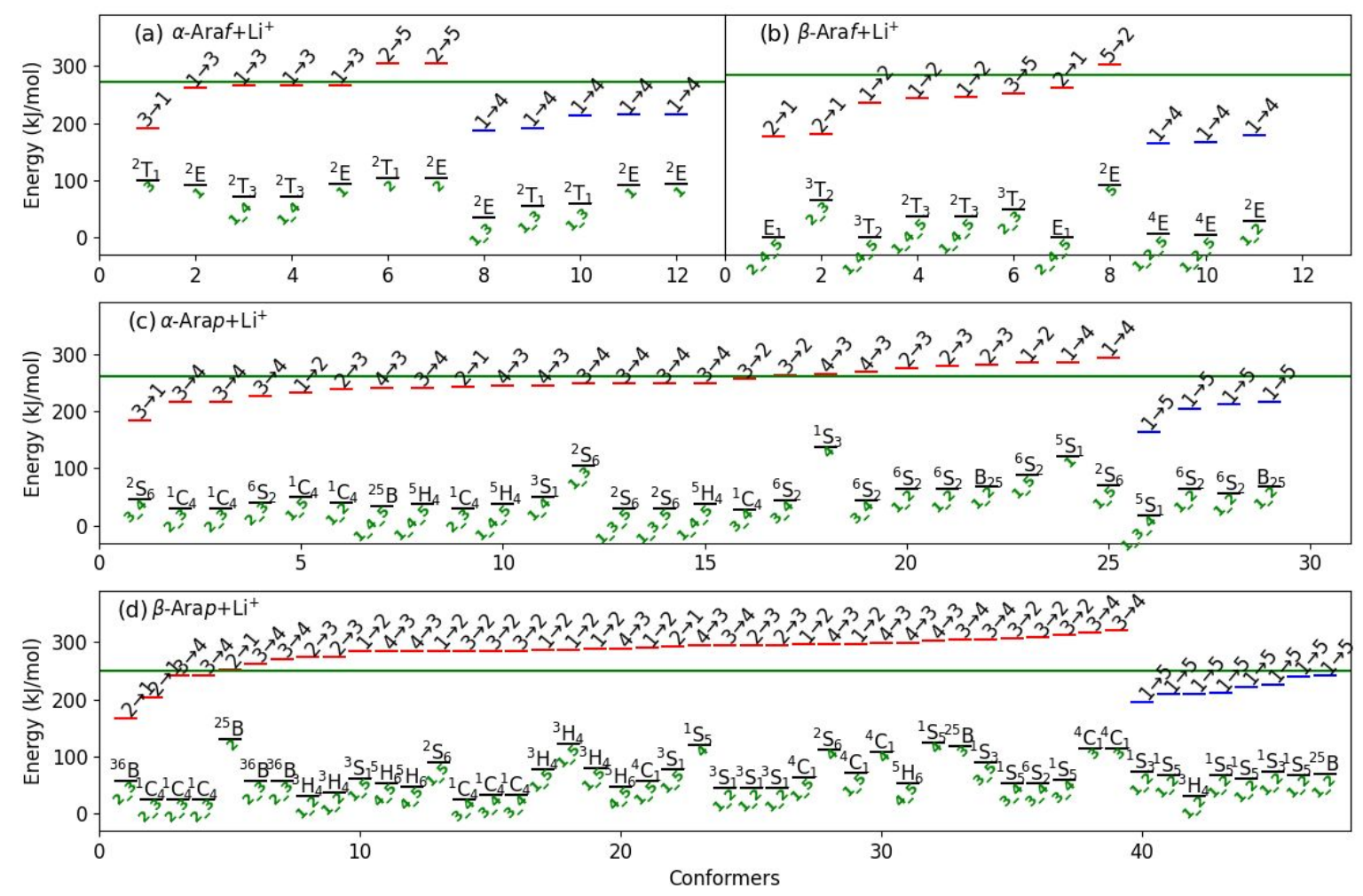

Figure 1S. The complete results of zero-point corrected energies of the transition states (TS) and the reactant states obtained from DFT/B3LYP calculations for Arabinose lithium adduct of isomer: (a) $\alpha$-Araf, (b) $\beta$-Araf, (c) $\alpha$-Arap and (d) $\beta$-Arap .
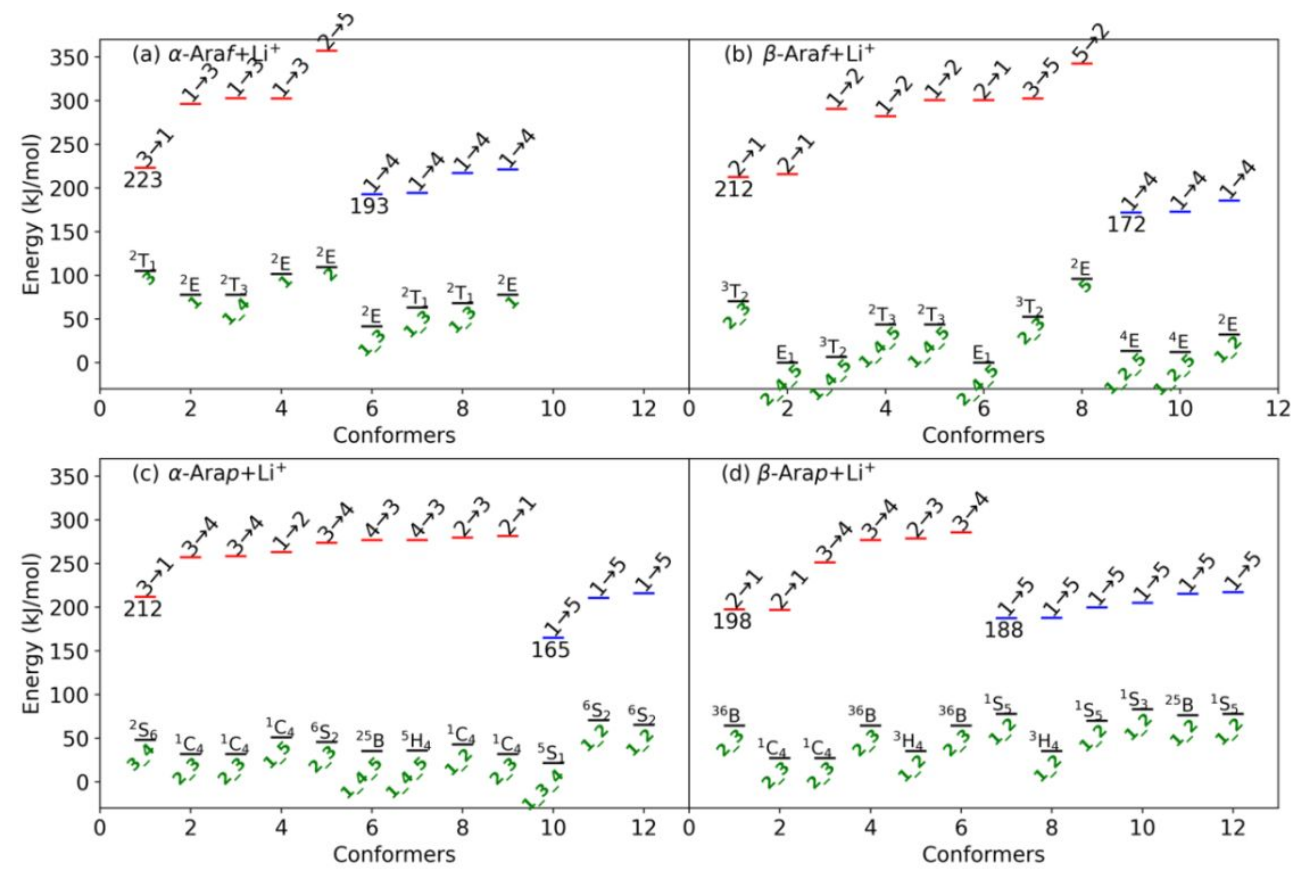

Figure 2S. The results of zero-point corrected energies of the transition states (TS) and the reactant states obtained from MP2 calculations for Arabinose lithium adduct of isomer: (a) $\alpha$ $\operatorname{Ara} f$, (b) $\beta$-Araf, (c) $\alpha$-Ara $p$ and (d) $\beta$-Arap. 

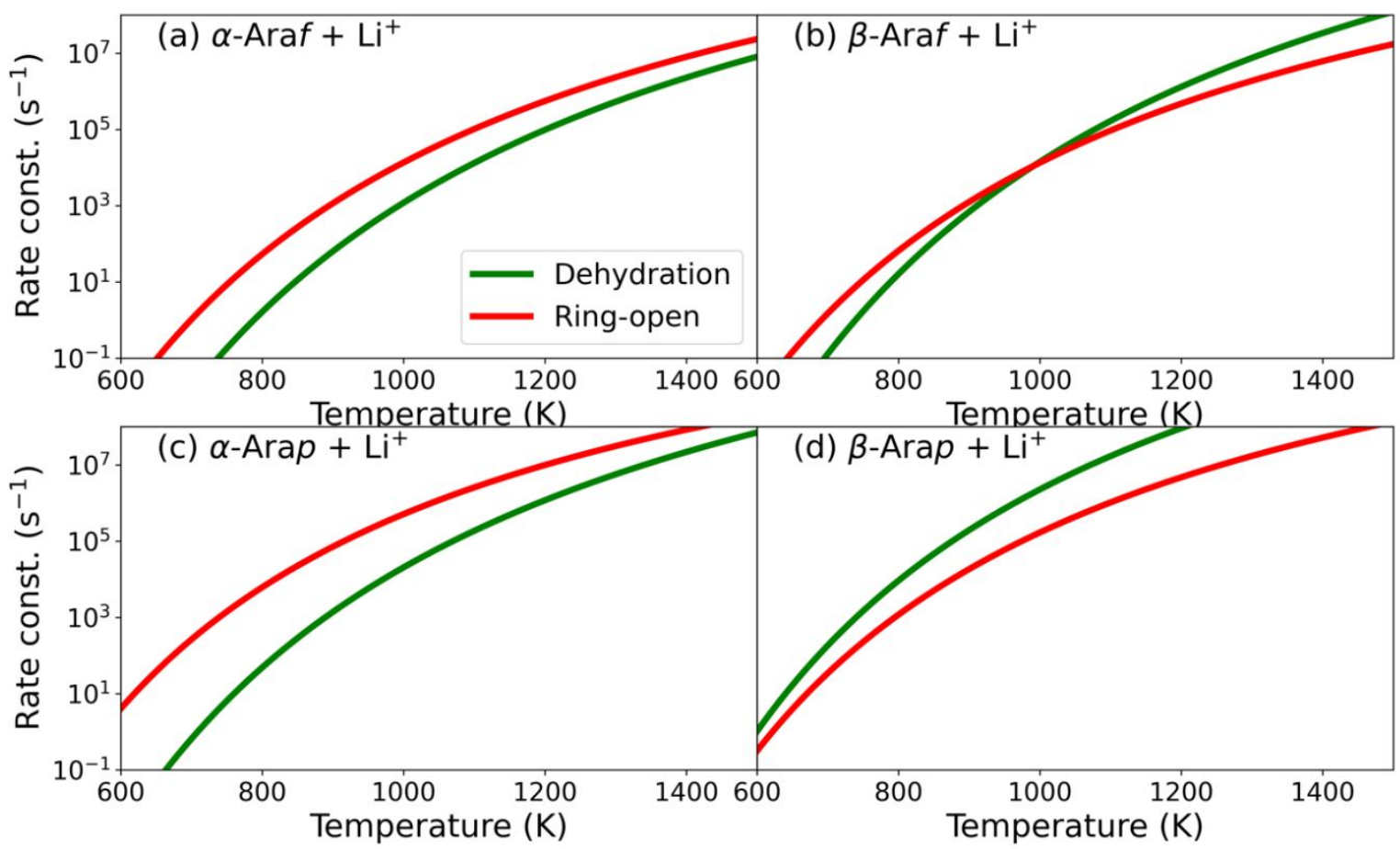

Figure 3S. Dissociation rate constants calculated with MP2 method for arabinose lithium adduct of isomer: (a) $\alpha$-Araf, (b) $\beta$-Araf, (c) $\alpha$-Arap and (d) $\beta$-Arap.
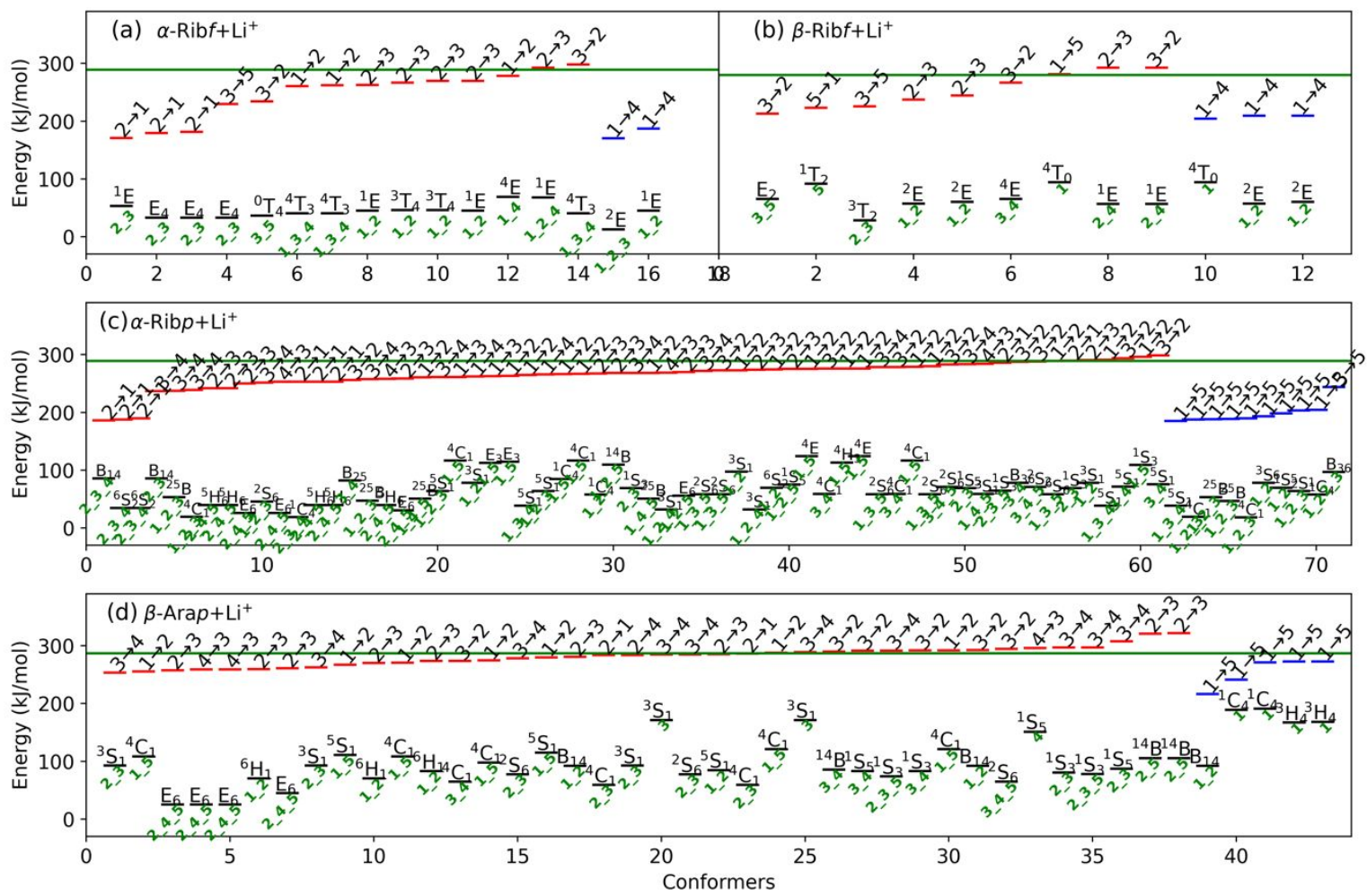

Figure 4S. The complete results of zero-point corrected energies of the transition states (TS) and the reactant states obtained from DFT/B3LYP calculations for Arabinose lithium adduct of isomer: (a) $\alpha$-Ribf, (b) $\beta$-Ribf, (c) $\alpha$-Rib $p$ and (d) $\beta$-Rib $p$. 

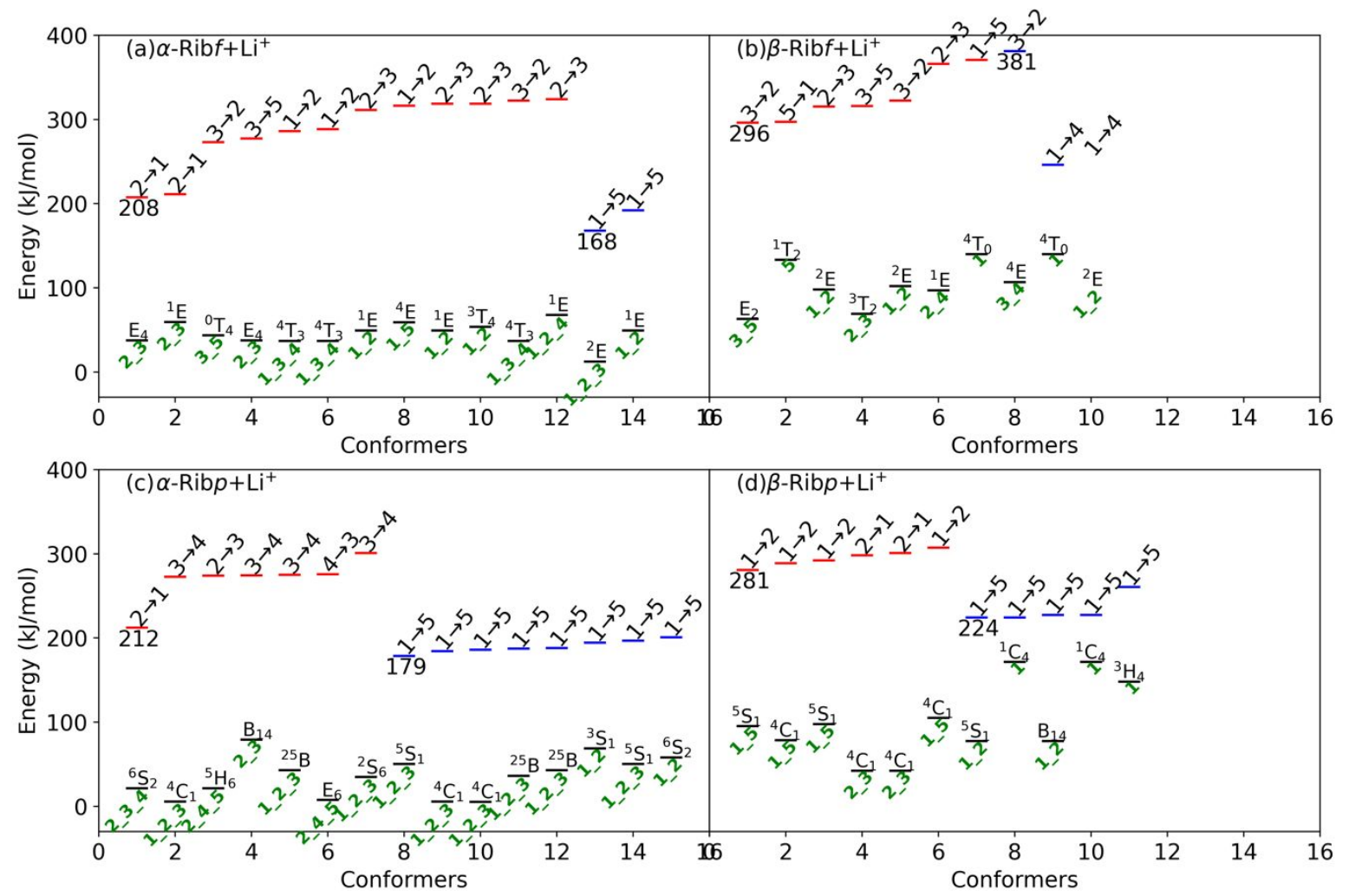

Figure 5S. The results of zero-point corrected energies of the transition states (TS) and the reactant states obtained from MP2 calculations for Arabinose lithium adduct of isomer: (a) $\alpha$ $\operatorname{Rib} f$, (b) $\beta$-Ribf, (c) $\alpha-\operatorname{Rib} p$ and (d) $\beta$-Rib $p$.
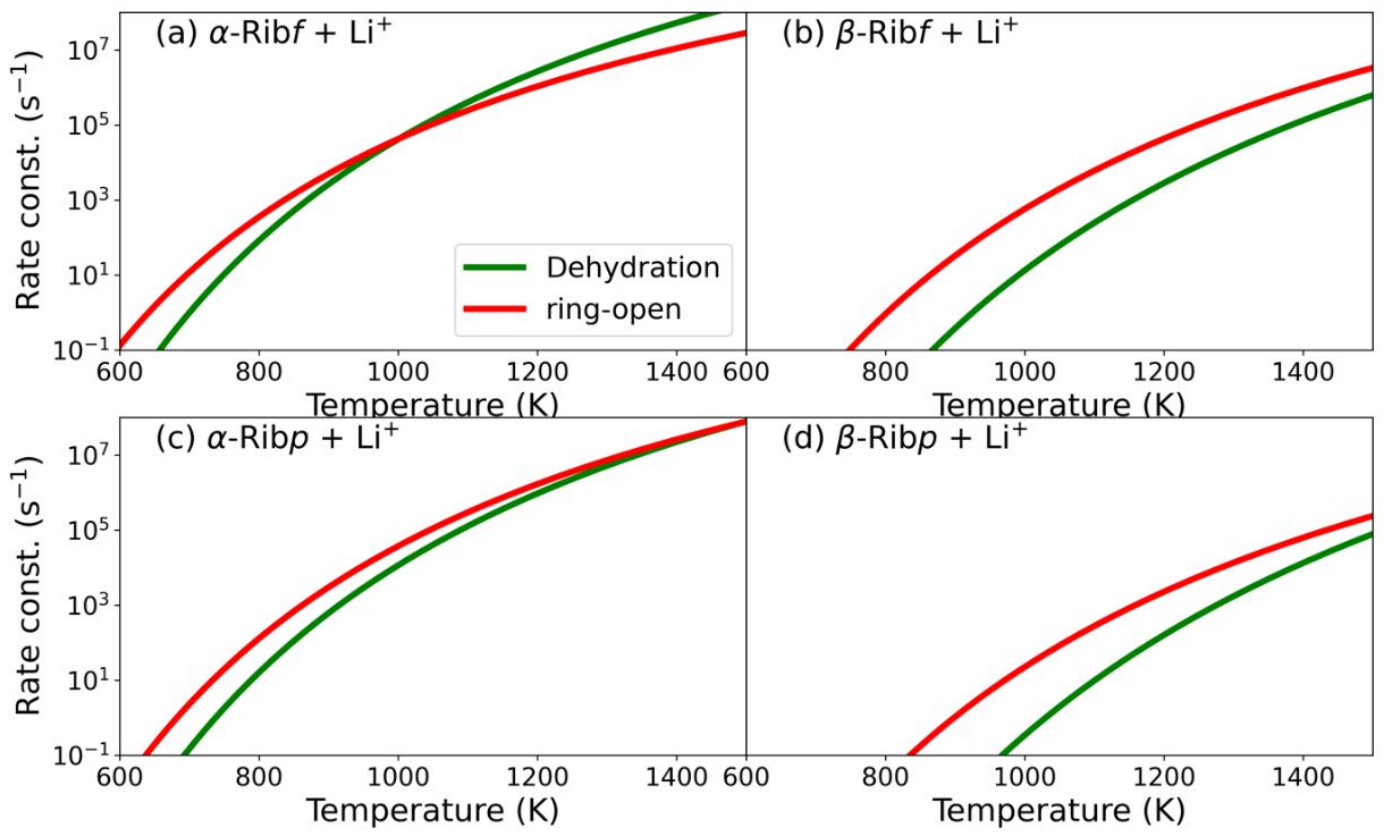

Figure 6S. Dissociation rate constants calculated with MP2 method for arabinose lithium adduct of isomer: (a) $\alpha$-Ribf, (b) $\beta$-Ribf, (c) $\alpha$-Ribp and (d) $\beta$-Ribp. 


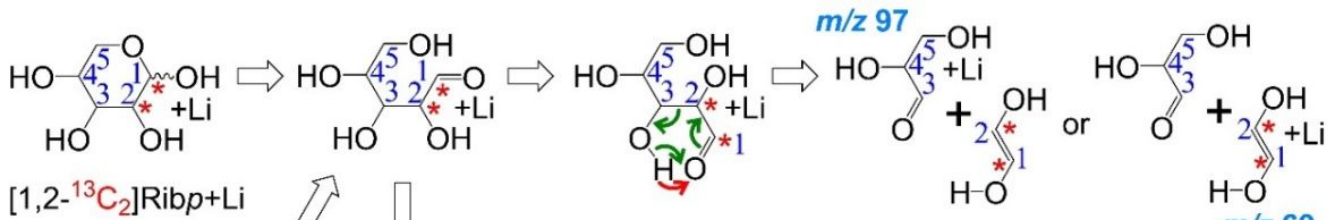

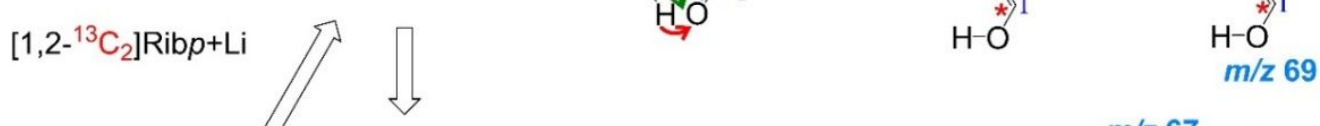

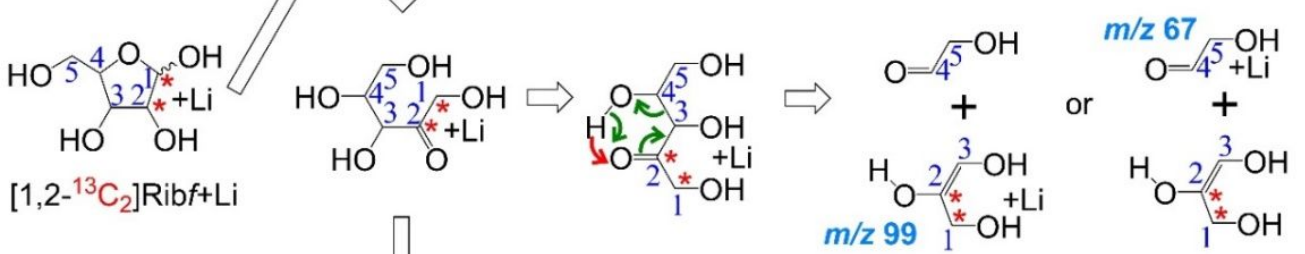

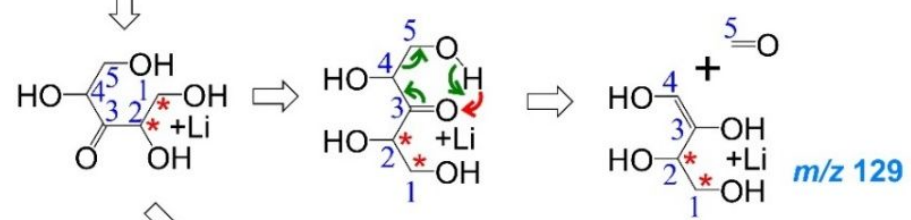

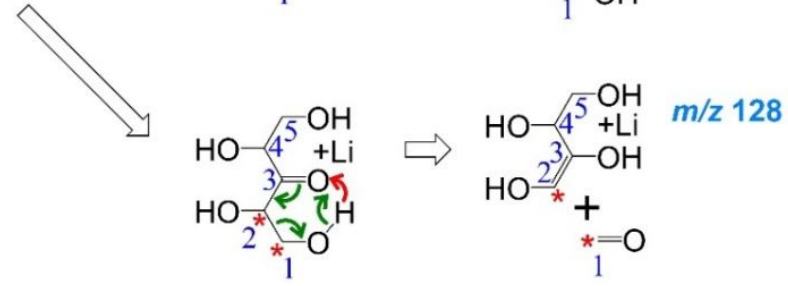

Figure 7S. Dissociation mechanisms of $\left[1,2-{ }^{13} \mathrm{C}_{2}\right]$ ribose in pyranose and furanose forms.

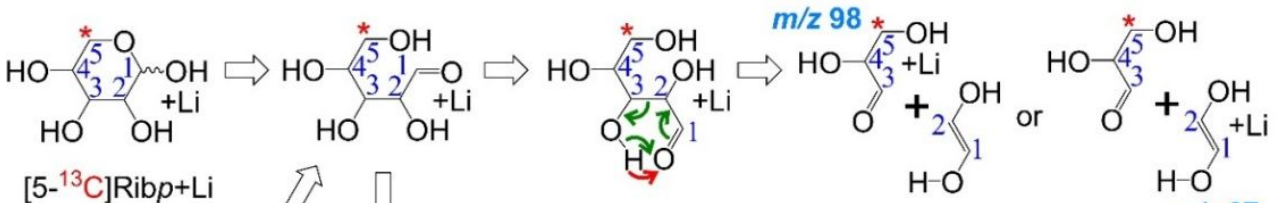

$$
\begin{aligned}
& {\left[5^{13} \mathrm{C}\right] \mathrm{Ribp+ \textrm {Li }} \gg \mathrm{H} \quad \begin{array}{cc}
\mathrm{H} \mathrm{O} & \mathrm{H}-\mathrm{O} \\
\mathrm{m} / \mathrm{z} & 67
\end{array}}
\end{aligned}
$$

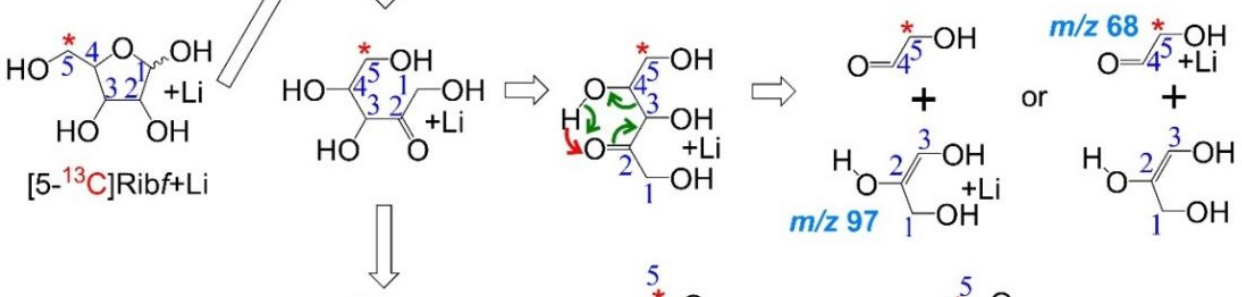

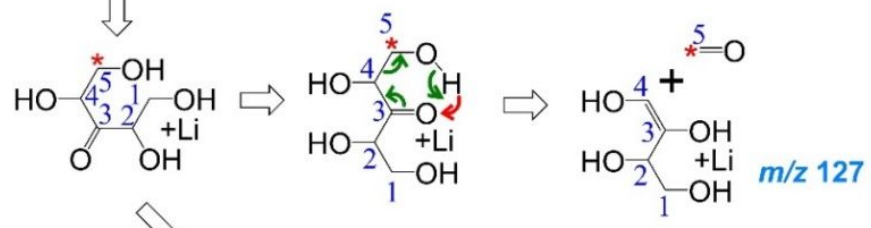

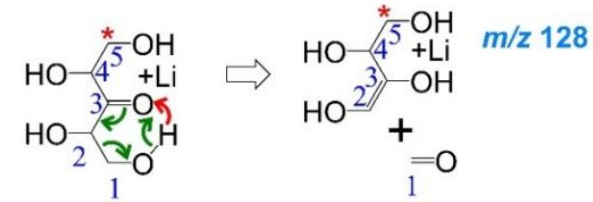

Figure $8 \mathrm{~S}$. Dissociation mechanisms of $\left[5-{ }^{13} \mathrm{C}\right]$ ribose in pyranose and furanose forms. 